\title{
A Perception Study Of Computer Science And Information Systems Students On Bullying Prevalence In The Information Systems Profession
}

James Lawler, Pace University, USA

John C. Molluzzo, Pace University, USA

\begin{abstract}
Bullying is considered to be omnipresent in business firms and prevalent in entrepreneurial firms in information systems and in departments of information systems in industry. Entrepreneurialism and narcissism of personalities in the information systems profession may be perceived as especially predisposed to bullying. The authors of this paper evaluate the knowledge of bullying by students in a leading school of computer science and information systems and learn that the students are essentially knowledgeable of bullying as a concern in industry. They learn that the knowledge of the students implies the importance of requisite sensitivity and professional standards in the profession and in the school. The paper may benefit educators in illuminating the issue of bullying for information systems students desiring to be in the profession.
\end{abstract}

Keywords: Bullying, Harassment; Information Systems Curricula; Information Systems Profession; Schools Of Computer Science And Information Systems; Sexism; Victimizing

\section{INTRODUCTION}

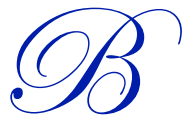

ullying is a critical issue in the country (Schoen, \& Schoen, 2010). Bullying is defined as "a form of aggression in which an individual, or groups of individuals, physically or psychologically harasses another individual over an extended period" (Hazler, Hoover, \& Oliver, 1992). In a firm or school, bullying is differentiated in a goal to cause continuing distress or harm in a relationship in which a perceived imbalance of power of an individual is an ingredient (Rigby, 2004). Bullying is an inappropriate method of increasing organizational or social stature (Parker-Pope, 2011, \& Swoboda, 2014). Extreme impacts of bullying in a firm (Cave, 2015) and a school (Shelton, 2010) are frequently cited in literature. Fundamental impacts of bullying in environments hostile to individuals constrain the morale and the performance of professionals in a firm and of students in a school of a university.

Bullying impacts negative physical problems (Martin, \& LaVan, 2010) and psychological problems, such as psychosomatic symptoms (Landstedt, \& Persson, 2014). Bullying impacts self-efficacy (McDonald, Brown, \& Smith, 2015) and self-esteem (Fryling, Cotler, Rivituso, Mathews, \& Pratico, 2014). Cyberbullying digital harassment of professionals and students is increasing with instant messenging and social networking technologies (Kowalski, \& Limber, 2007, \& Dickey / Riga, 2014), and the harassment is influencing other psychosomatic symptoms. The impacts of a bullying culture in a firm or in school are clear in the costs (Cortina, 2008, \& Field, 2009) of lower innovation and productivity of professionals and students and the lower reputation of the industry or the university. Firms and schools have a higher potential for innovation with heterogeneous professionals and students on project teams not impacted by the issue of bullying (Nelson, 2014).

Estimates (Namie, 2014) indicate 27\% of professionals experience physical, psychological or verbal bullying in industry. Estimates (Computer Weekly, 2008) further indicate $63 \%$ of information systems professionals experience bullying in industry, citing changing goals of managers, constant criticism of managers on minor problems, doing 
marginalized projects, excessive minutia monitoring, explanations of managers not clear, mean-spiritedness of professionals, lots of projects, or not enough projects. In the literature (Namie, 2014), managers are $55 \%$ of bullying perpetrators. The results of surveys (Namie, 2014) indicate $69 \%$ of the perpetrators are male professionals, and $57 \%$ of their victims are female professionals, on project teams. Surveys (Namie, 2014) indicate a distressing $71 \%$ of the cultures of firms condone bullying, if not discrimination and sexual harassment (Kristof, 2014), as a feature in the industry (Cave, 2014b), an issue that may contribute to diverse perceptions on meritocratic performance by students, as they pursue information systems as a future profession.

\section{INFORMATION SYSTEMS AS A FERTILE FIELD FOR BULLYING INCIDENTS}

In this paper, the authors evaluate the knowledge of bullying in the perceptions of students at Pace University. Bullying is evidently a feature of the field in departments of information systems in industry and post-secondary schools (Education Portal, 2010). Entrepreneurialism and narcissism of people in the industry (Fontane, 2014), such as Steve Jobs, may cause people to believe the profession is predisposed to bullying (Summers, 2015). Extroverted personalities may be prone to bullying and insensitivity to introverted personalities in the profession (Cave, 2014a). Mobility in the information systems profession may be premised on politics predisposed to bullying (Cave, 2014c). Perceptions of students may indicate bullying may be a norm (Rigby, 1999) and not an issue. Perceptions of students may indicate bullying of ethnic, female gender, homophobic, racial or religious professionals in the industry, or in school settings, may be a norm and not an overt or subtle issue in the profession. In short, the perceptions of students in a school of information systems of a university may indicate that bullying prevalence and sexism in technology are not enough of a problem that they might be hesitant about advancing in this lucrative profession.

However, bullying prevalence against female professionals is noted to be an issue in the information systems profession. Literature indicates initial instances of this particular problem in post-secondary school settings (PerezPena, 2014, Steinhauer, 2014, \& Wilkinson, 2015). Literature further shows the issue prominently in information systems technology in the Silicon Valley (Streitfeld, 2015a, Streitfeld, 2015b, Suddath, 2015, \& The Economist, 2015). Moreover, bullying and harassment prevalence of gay and lesbian professionals is noted similarly in technology (Thibodeau, 2015). Nevertheless, bullying prevalence, including sexual harassment as an inequality problem (Manjoo, 2015, \& Wingfield, 2014), may be placated by proactive professionals for parity rights in technology (Ceci, Ginther, Kahn, \& Williams, 2015). The perceptions of female and male students indicate that such professionals may be interim models if not motivators for them to pursue and persevere in the profession. The potential of a revolution to proscribe bullying prevalence and sexism (Stone, 2015) may motivate students in schools of information systems in a university. The profession may benefit having increased numbers of new nonrepresentative at risk students in technology (DuBow, 2014).

Therefore, this paper posits a research study to evaluate the knowledge of bullying of the students of Pace University, as to their perceptions of the problem in the industry and the university. Bullying may be inevitably perceived by students to be merely a behavioral norm in the information systems profession and society (Wolf, 2013). Might the students not be knowledgeable of bullying incidents in the profession and the university? Might the students not be knowledgeable of bullying and sexism as a problem in the profession? Might the students not be knowledgeable of institutional mandates of pre-emption of the problem in the profession and the university (Galanes, 2014)? Might not enough of the students, or friends of the students, be bullying victims? Might not enough of the female, gay and lesbian students among them be bullying and sexism victims? The findings of this paper may be elucidating for educators in information systems, given the literature on bullying prevalence and sexism in the profession and in post-secondary schools (Belkin, 2015, Rubenfeld, 2014, \& Steinhauer, \& PerezPena, 2014). The perceptions of the information systems students on bullying may be illuminating in favoring, or not favoring, increased inclusion of the issue in the curricula of schools of computer science and information systems of a university.

\section{FOCUS OF STUDY}

The focus of the authors is to evaluate the perceptions of information systems students on bullying prevalence in the information systems profession and in the university. The authors hope to learn if bullying is perceived as a 
problem realistic and serious by the students. The importance or non-importance of the problem, individually perceived by female students and by male students, may highlight the moral nature of the profession and the need of new professional standards in schools of computer science and information systems (Stanford Encyclopedia of Philosophy, 2012). The perceptions on bullying and sexism may further highlight the need of proactive processes and resolution sources for all professionals and for all students, not nonchalant responses, in the event of victimizing. This paper may be an eventual foundation for helping information systems students navigate the problem of bullying in the profession and in the university.

\section{METHODOLOGY}

The research methodology of this paper was focused on an anonymous e-mailed Likert-like perception survey of 226 graduate and undergraduate students, in Pace University, in January - March 2015. The instruments of survey included 47 items on knowledge of bullying incidents and perceptions of issues in the information systems profession, school and university of 182 existing graduate and undergraduate students, mostly employed fully or partly in information systems positions. The instruments further included 24 items on knowledge of bullying and perceptions of issues in the school and university of 44 new undergraduate students. The instruments indicated in the preface to the survey that the responses of the students were to be protected as private by the authors.

The methodology of the process of the surveying was, in proven reliability (Frankfort-Nachmias, \& Leon-Guerrero, 2015), similar to the methodology of the surveying of the authors on cyberbullying in previous years at the University (Molluzzo, \& Lawler 2011, Molluzzo, Lawler, \& Manneh, 2012, \& Molluzzo, \& Lawler, 2013).

The item questions on the instruments of the survey were approved for integrity in design, privacy and security, and sensitivity by the Dean for Students, the Institutional Review Board (IRB) and the Provost of the university, before the student surveying in 2015 .

The responses from the survey were evaluated by the authors using Qualtrics and SPSS (McClave, Sincich, \& Mendenhall, 2007, \& Wagner III, 2015) in April - May 2015.

The instrument of survey is available upon request of the first author.

\section{ANALYSIS OF DATA AND IMPLICATIONS OF STUDY}

\section{Demographic Data}

A total of 142 survey responses were submitted, $68 \%$ male and $32 \%$ female. Not every submission was completed. Table 1 shows the ethnicity of the respondents, which reflects the ethnicity of the school. Of that reporting, $27 \%$ identified themselves as international students. The majority of respondents, $74 \%(n=90)$, were graduate students. Of the 32 undergraduate respondents $66 \%(\mathrm{n}=21)$ were upper-level (Junior/Senior) students.

Table 1

\begin{tabular}{l|cc}
\hline & Responses & $\%$ \\
\hline African American & 19 & $13.8 \%$ \\
\hline Asian American & 24 & $17.5 \%$ \\
\hline Hispanic & 15 & $10.9 \%$ \\
\hline Muslim & 4 & $29 \%$ \\
\hline White & 64 & $46.7 \%$ \\
\hline Other & 11 & $8.0 \%$ \\
\hline
\end{tabular}

The survey also asked about employment experience in the information systems industry. $55 \%$ of the respondents (out of 113) were previously or currently full-time employed in an information systems position. $46 \%$ of respondents (out of 113) were previously or currently part-time employed in an information systems position. 


\section{Bullying: The Information Systems Profession}

Of those respondents who reported part- or full-time information systems employment $48 \%$ (out of 77) reported that they believed that bullying is an issue in the information systems industry. This implies that the students of this study are fundamentally knowledgeable of bullying as a culture in the industry. Respondents indicated they learn of this bullying as a feature of the profession from other professionals. $43 \%$ (out of 77) indicated that they have heard of bullying in the information systems industry from other industry professionals, while $38 \%$ (out of 77 ) indicated that they have read about information systems industry bullying in practitioner publications. As far as personal experience of bullying, $32 \%$ (out of 77) reported encountering bullying in the information systems positions they have held in industry.

Importantly, as shown in Table 2, a high number of the information systems students indicate bullying in the information systems profession as an equivalent issue in large-sized and small-sized firms.

Table 2

\begin{tabular}{l|c|c|c|c}
\hline \multicolumn{5}{|c}{ Do you feel that bullying would be less/more likely in the following types of industries? } \\
\hline \multicolumn{1}{|c|}{ Question } & Less likely & The same & More likely & Total Responses \\
\hline Large technology firms (IBM, Oracle, etc. & $29(41.4 \%)$ & $22(31.4 \%)$ & $19(27.1 \%$ & 70 \\
\hline Mid-sized technology firms & $15(21.4 \%)$ & $49(70 \%)$ & $6(8.6 \%)$ & 70 \\
\hline Small technology firms & $21(30 \%)$ & $26(37.1 \%)$ & $23(23.9 \%)$ & 70 \\
\hline Start-up (entrepreneurial) technology firms & $27(38.6 \%)$ & $24(34.3 \%)$ & $19(27.1 \%)$ & 70 \\
\hline
\end{tabular}

The issue is not merely a problem of the profession but society (Thompson, 2015). The negative perceptions of the issue by the students may encourage instructors in information systems in guiding them through this problem.

\section{Bullying: Sexism and Minorities}

The findings further imply that the students in Pace University are especially knowledgeable of bullying and sexism as features of the information systems profession. 37 out of the 77 students $(48.1 \%)$ who had part-time or full-time employment experience believed that bullying is an issue in the information systems profession, while 42 of 69 respondents $(60.9 \%)$ believe that females are more likely to be bullied than any other group. Table 3 shows that students indicate that female professionals, gay and lesbian professionals, and professionals with disabilities are more predisposed than other professionals to be bullying and sexism victims.

Table 3

\begin{tabular}{l|c|c|c|c}
\hline \multicolumn{5}{c}{ Do you feel that any of the following are more or less likely to be victims of bullying? } \\
\hline \multicolumn{1}{c}{ Question } & Less likely & $\begin{array}{c}\text { Same as any other } \\
\text { group }\end{array}$ & More likely & Total Responses \\
\hline Females & $5(7.2 \%)$ & $22(31.9 \%)$ & $42(60.9 \%)$ & 69 \\
\hline African-Americans & $6(8.8 \%)$ & $35(51.5 \%)$ & $27(39.7 \%)$ & 68 \\
\hline Asian-Americans & $6(8.8 \%)$ & $36(52.9 \%)$ & $26(38.2 \%)$ & 68 \\
\hline Hispanics & $4(5.9 \%)$ & $39(58.2 \%)$ & $24(35.8 \%)$ & 67 \\
\hline Muslims & $6(8.7 \%)$ & $31(44.9 \%)$ & $32(46.4 \%)$ & 69 \\
\hline Gays or Lesbians & $4(5.9 \%)$ & $24(35.3 \%)$ & $40(58.8 \%)$ & 68 \\
\hline Disabled persons & $15(22.1 \%)$ & $27(39.7 \%)$ & $26(38.2 \%)$ & 68 \\
\hline
\end{tabular}

The bullying and the sexism in technology may be overt or subtle but is undesirable even if unreported by victims (Chemaly, 2014). The issue is a problem in a profession eager for more female, gay and lesbian students and those with disabilities (Rosenberg, 2014, \& Williams, 2014). The negative perceptions of the prevalence of this issue by these students may entice organizations and schools of information systems in helping in navigating them through this problem.

The survey inquired if the respondents felt that bullying in the information systems industry is enough of a problem that it should be covered in a required ethics course. $70 \%$ of the respondents indicated Yes or Maybe. This result implies that bullying and sexism in the information systems profession might be mitigated by best models of 
practices of productivity and professionalism in the industry. The importance of meritocracy in professional standards on innovation project teams in technology (Whitney, \& Ames, 2014), and initially on project teams in schools of information systems, is indicated notably by the female students. Table 4 shows that female students while at work encountered bullying more than their male counterparts.

Table 4

\begin{tabular}{l|c|c|c}
\hline & Was the bullying you encountered by any of the following? & Total \\
\hline & Male & Female & 21 \\
\hline A manager & $14(66.7 \%)$ & $7(33.3 \%)$ & 11 \\
\hline A peer & $7(63.6 \%)$ & $4(36.4 \%)$ & 3 \\
\hline A subordinate & $0(0.0 \%)$ & $3(100.0 \%)$ & 4 \\
\hline An external consultant & $1(25.0 \%)$ & $3(75.0 \%)$ & 24 \\
\hline Total & 17 & 7 & \\
\hline
\end{tabular}

The particular perceptions of these students may entice instructors in schools of information systems in imparting more requisite responsibilities and standards in their teaching of technology.

\section{Bullying: The University}

This study implies the importance of providing inclusion on the problem and the potential resolution of bullying in the profession in the pedagogy of schools of information systems. Though most of the students indicate that they were not knowledgeable of incidents of bullying (only 3 of 119 respondents) in Pace University, and most of them indicate in the survey that they were not victims ( 6 of 114 claims to be victims), as discussed previously most of them were knowledgeable of incidents of bullying prevalence and sexism in the information systems profession. The perceptions of these students may influence instructors in schools of information systems in imparting more inter-personal skills, not merely skills in technology, in their teaching, so that students might be more prepared and sensitive to the bullying and the sexism when they graduate into organizations.

There are two university courses taken by all undergraduate students. UNIV 101 is a required course that introduces students to living in the university and to project management and time management skills and other such soft skills. CIS 101 is a required University core course in computing. The results in Table 5 imply that bullying might be mitigated by more prevention processes in a university by discussing the problem in appropriate courses.

Table 5

\begin{tabular}{l|c|c}
\hline \multicolumn{3}{c}{ Bullying is enough of a problem that it should be } \\
\hline & Yes & No \\
\hline Discussed in UNIV 101 & $10(34 \%)$ & $19(66 \%)$ \\
\hline Discussed in CIS 101 & $4(14 \%)$ & $25(86 \%)$ \\
\hline Covered in IT courses as part of professional standards & $71(62 \%)$ & $43(38 \%)$ \\
\hline
\end{tabular}

The importance of intervention and preventive processes, and resolution sources (Clifford, 2012), is indicated by most of the students (see row three of Table 5), notably by the female students -25 of 34 female students (73.5\%) responded Yes.

Of those students (12) who were aware of bullying incidents at the university, $75 \%$ responded that the professor was not responsive enough to the situation. Also, $67 \%$ of these same students indicated that the administration of the school was not responsive to the problem of bullying. The perceptions of these students on bullying preventive processes may instigate more proactive procedures of non-tolerance of bullying in schools of information systems and universities. 


\section{LIMITATIONS OF STUDY AND OPPORTUNITIES}

This study on the bullying perceptions by students in one school of one urban university may not be generalized without caution. The perceptions of bullying in the industry by existing students may be enhanced in the inclusion of the perceptions of more matriculated students in the profession. The perceptions of bullying and sexism in the information systems profession in contrast to non-information systems professions may be evaluated further in a future study. However, this study is helpful in learning the perceptions of information systems students, as to the realities of bullying initially in post-secondary schools and then in the profession, so that instructors in the schools might prepare an improved navigational path for them. The field of bullying in the information systems profession and other professions furnishes increasing opportunities for researchers (Lester, 2009).

\section{CONCLUSION}

Bullying is a concern in the information systems profession. The findings on the perceptions of bullying by the information systems students denote knowledge of bullying as a problem in this profession. The perceptions of most of the students that female professionals, gay and lesbian professionals and professionals with disabilities are more predisposed than other professionals to be bullying victims are denoted in this study. Female students are denoted especially knowledgeable of the problems of bullying and sexism. Though most of the perceptions of the students were not of rampant bullying, and most of the students were not bullying or sexism victims, the perceptions of the students are of a prevalence realistic and serious to them. Schools of information systems might navigate students through the problems of bullying and sexism so that information systems students are more prepared for organizational realities. Those in the schools might provide projects on professional responsibilities and standards of successful technologists on teams so that the students are more prepared for problems and solutions. Schools might further provide more inter-personal sensitivity skills to these studentso that they will not be geeks or pure technologists. This study suggested that universities might be more supportive of students, especially if these students are victimized by bullying or sexism. In conclusion, the perceptions of the students in this study provide a snapshot of bullying realities and interim solutions that is timely.

\section{AUTHOR INFORMATION}

Dr. James P. Lawler is Professor of Disability Studies and Information Technologies in the Seidenberg School of Computer Science and Information Systems at Pace University in New York City and is recognized with the Jefferson Award for Community Service. Email: jlawler@pace.edu

Dr. John C. Molluzzo is Professor of Information Technologies in the Seidenberg School at Pace University. Email: Email: jmolluzzo@pace.edu

\section{REFERENCES}

Belkin, D. (2015). Dartmouth bans hard liquor on campus: Elite college joins other schools in responding to party culture that has tarnished their reputations in recent years. The Wall Street Journal, January 30, A3.

Cave, K. (2014a). Introverts vs. extroverts in technology. IDG Connect, April 3, 5.

Cave, K. (2014b). Is bullying rife in technology? IDG Connect, May 21, 2-7.

Cave, K. (2014c). Information technology careers: Success vs. bullying. IDG Connect, August 4, 6.

Cave, K. (2015). A protest workplace bullying suicide. IDG Connect, January 28, 2-3.

Ceci, S.J., Ginther, D.K., Kahn, S., \& Williams, W.M. (2015). Women in science: The path to progress. Scientific American Mind, 26(1), 1-10.

Chemaly, S. (2014). How did the Federal Bureau of Investigation miss over one million rapes? The Nation, June 27, 1-11.

Clifford, M. (2012). Fifteen strategies educators can use to stop cyberbullying. InformEd, November 6, 1-3.

Cortina, L. (2008). Unseen injustice: Incivility as modern discrimination in organizations. The Academy of Management Review, $33,55-75$.

Dickey / Riga, J. (2014). The antisocial network inside the dangerous online world kids cannot quit. Time, June 26, 40-45.

DuBow, W. (2014). Attracting and retaining women in computing. IEEE Computer, 0018-9162(14) 90-93.

Field, T. (2009). Bully in sight: How to predict, resist, challenge and combat workplace bullying. London, United Kingdom: Success Unlimited.

Fontane, M.P. (2014). The perception of workplace bullying directed against information technology auditors. Walden 
University, 1-125.

Frankfort-Nachmias, C., \& Leon-Guerrero, A. (2015). Social statistics for a diverse society, $7^{\text {th }}$ Edition. Thousand Oaks, California: Sage Publications, Inc.

Fryling, M., Cotler, J., Rivituso, J., Mathews, L., \& Pratico, S. (2014). Cyberbullying or normal game play: Impact of age, gender, and experience on cyberbullying in multi-player online gaming environments - Perceptions from one gaming forum. 2014 Proceedings of the Information Systems Educators Conference (ISECON), 7(3307), Baltimore, Maryland, $1-15$.

Galanes, P. (2014). Seeking a level playing field: Kristen Gillibrand and Julianna Margulies share more than fame. The New York Times, October 24, 4.

Hazler, R.J., Hoover, J.H., \& Oliver, R. (1992). What kids say about bullying. Executive Editor, 14(11), 20-22.

Kowalski, R.M., \& Limber, S.P. (2007). Electronic bullying among middle school students. Journal of Adolescent Health, 41 , S22-S30.

Kristof, N. (2014). Bill Cosby, University of Virginia and Rape. The New York Times, November 27, 25.

Landstedt, E., \& Persson, S. (2014). Bullying, cyberbullying, and mental health in young people. Scandinavian Journal of Public Health, 42(4), 393-399.

Lester, J. (2009). Not your child's playground: Workplace bullying among community college faculty. Community College Journal of Research and Practice, 33, 446-464.

Manjoo, F. (2015). Loud voice for women in technology was foiled by his tone. The New York Times, February $26, \mathrm{~B} 1$, B11.

Martin, W., \& LaVan, H. (2010). Workplace bullying: A review of litigated cases. Employee Responsibilities and Rights Journal, 22(3), 175-194.

McClave, J., Sincich, T., \& Mendenhall, W. (2007). Statistics, $11^{\text {th }}$ Edition. Upper Saddle River, New Jersey: Pearson Prentice Hall.

McDonald, D.N., Brown, E.D., \& Smith, K.F. (2015). Workplace bullying: A review of its impact on businesses, employees, and the law. International Journal of Business and Social Justice, 6(2), 27.

Molluzzo, J.C., \& Lawler, J.P. (2011). A study of the perceptions of college students on cyberbullying. 2011 Proceedings of the Information Systems Educators Conference (ISECON), 28(1633), Wilmington, North Carolina, 1-25.

Molluzzo, J.C., Lawler, J., \& Manneh, J. (2012). A comprehensive survey on cyberbullying perceptions at a major metropolitan university - Faculty perspectives. 2012 Proceedings of the Information Systems Educators Conference (ISECON), 29(1918), New Orleans, Louisiana, 1-20.

Molluzzo, J.C., \& Lawler, J.P. (2013). A comparison of faculty and student perceptions of cyberbullying. 2013 Proceedings of the Information Systems Educators Conference (ISECON), 30(2533), San Antonio, Texas, 1-17.

Namie, G. (2014). 2014 Workplace Institute United States Workplace Bullying Survey. Workplace Bullying Institute.

Nelson, B. (2014). The data on diversity. Communications of the ACM, 57(11), 86-95.

Parker-Pope, T. (2011). Web of popularity achieved by bullying. The New York Times, February 15, 1,6.

Perez-Pena, R. (2014). Rare survey examines sex assault at Massachusetts Institute of Technology: An in-depth look at campus incidents. The New York Times, October 28, A18,A23.

Rigby, K. (1999). What harm does bullying do? Proceedings of the Children and Crime: Victims and Offenders Conference, Brisbane, Australia.

Rigby, K. (2004). Addressing bullying in schools: Theoretical perspectives and their implications. Social Psychology International, 25(3), 287-300.

Rosenberg, D. (2014). Cracking the code: By teaching young girls of color how to program computers, one engineer hopes to change the face of technology. Smithsonian, November, 54-59.

Rubenfeld, J. (2014). Mishandling rape: Colleges are seeing sexual assault where it does not exist while letting dangerous men go free. The New York Times Sunday Review, November 16, 1,4.

Schoen, S., \& Schoen, A. (2010). Bullying and Harassment in the United States. Boca Raton, Florida: Routledge: Taylor \& Francis Group.

Shelton, J.C. (2010). Online cyberbullying: Role of social media in teen suicide. Hub Pages, 1-2.

Steinhauer, J. (2014). Widening spotlight on assault of women. The New York Times, December 5, A14,A20.

Steinhauer, J., \& Perez-Pena, R. (2014). University's image suffers after campus rape report: Allegation stirs debate at Virginia on assaults and role of fraternities. The New York Times, November 25, A15,A19.

Stone, B. (2015). Valley of the boys. Bloomberg Business Week, March 17, 14-16.

Streitfeld, D. (2015a). A Silicon Valley harassment trial casts a long shadow: Big potential implications for the conversation in the valley. The New York Times, February 23, B1,B3.

Streitfeld, D. (2015b). Venture capitalists under spotlight in bias suit: A Silicon Valley case points to a dearth of female leaders. The New York Times, March 6, 1,B2.

Suddath, C. (2015). Girl code: A big documentary on Silicon Valley's sexism problem. Bloomberg Business Week, May $14,1$.

Summers, N. (2015). Return of the boom-boom room. Bloomberg Business Week, March, 8-9.

Swoboda, E. (2014). Cyberbullying. Scientific American Mind, 25(6), 46-53.

Thibodeau, P. (2015). Indiana's law delivers real hurt to this state technology graduate. Computerworld, March 30, 1-6.

Thompson, C. (2015). Some groups say 'Fifty Shades' endorses sexual violence. Fox News, February 12, 1. 
Wagner III, W.E. (2015). Using IBM SPSS Statistics for Research Methods and Social Science Statistics. Thousand Oaks, California: Sage Publications, Inc.

Whitney, T., \& Ames, E. (2014). Broadening participation: What technology companies, especially startups, need to know about building great places to work - for her and him - in the digital age. Communications of the ACM, 57(12), 28-30.

Wilkinson, J. (2015). My University of Virginia story. The New York Times Sunday Review, April 5, 1,6.

Williams, J.C. (2014). Hacking technology’s diversity problem: To bring more women into the sector, companies should try a lean start-up approach. Harvard Business Review, October, 94-100.

Wingfield, N. (2014). Microsoft chief sets off a furor on women's pay. The New York Times, October 9 B1,B7.

Wolf, E. (2013). Is it bullying, or is it just bad behavior? The New York Times, March 13, 1-2. (2008). Bullying in the information systems profession. Computer Weekly, December.

(2010). Cyberbullying: A national epidemic. Education Portal, October 6, 1-2.

(2012). Information technology and moral values. Stanford Encyclopedia of Philosophy, June 12.

(2015). Valley of the dudes. The Economist: Schumpeter, April 4, 64. 